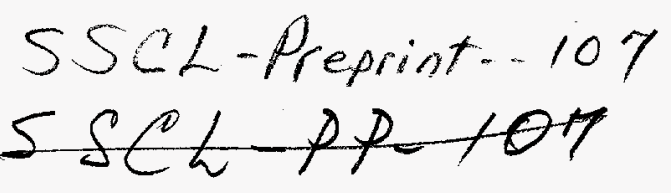

\title{
A METHOD OF LINES SOLUTION OF THE TRANSIENT BEHAVIOR OF THE HELIUM COOLED POWER LEADS FOR THE SSC
}

\author{
J. A. Demko, W. E. Schiesser, R. Carcagno, and M. McAshan \\ Superconducting Super Collider Laboratory ${ }^{1}$ \\ 2550 Beckleymeade Ave. MS 4003 \\ Dallas, Texas 75237-3946
}

\begin{abstract}
In this study, a detailed numerical thermal mode. of a $6.5 \mathrm{kA}$ power lead for the Superconducting Super Collider has been developed, which was adapted from the dynamic model developed by Schiesser[1]. The transient behavior of the power leads was modeled using a method of lines (MOL) approach. The model was developed to provide a tool for analyzing coolant control strategies as well as an understanding of the behavior of the leads under presumed system transients. Results for a current ramp up to 4970 amps are favorably compared with measurements. Also, a loss of cooling situation is predicted to determine the transient temperature distribution under an off-design condition.
\end{abstract}

\section{INTRODUCTION}

The Superconducting Super Collider (SSC) is a high-energy proton accelerator that is being designed and constructed in Texas, just south of Dallas. When the SSC comes on line in the year 2000 , it will be the world's largest scientific instrument, with a main ring 87 $\mathrm{km}$ (53 miles) in circumference. The SSC will probe the structure of matter at scales below $10^{-18} \mathrm{~m}$ to determine if quarks, of which neutrons and protons are composed, are the ultimate particles of matter. In particular, the SSC will be used to search for the top quark if existing accelerators at Fermilab and Cem are unable to find the top in intervening years, and to investigate other aspects of the structure of matter and the fundamental forces within the context of the Standard Model. Also, the SSC will create conditions which are thought to have existed $10^{-18}$ seconds after the Big Bang [2].

The accelerating of protons to the 20 Tev level requires powerful steering magnets to be placed around the main ring. The required 6.6 Tesla field can be practically achieved only through the use of low temperature superconducting magnets which will be cooled to $4 \mathrm{~K}$ using supercritical helium (He). Thus, electrical power must be delivered from ambient temperature as received from the local power grid to the magnets operating at $4 \mathrm{~K}$. This requirement is achieved using a power lead which must operate through a temperature drop from ambient to $4 \mathrm{~K}$. The design of the SSC power leads can significantly affect their performance and efficiency, and therefore the overall power consumption of the SSC.

The normal operation and performance optimization of cryogenic current leads has been the subject of many investigations [1,3-8]. The transient behavior of helium cooled current leads has also been investigated by Jones et. al. [7] and Aharonian et. al. [8] Jones investigated the response of a lead to a current overload pulse, and determined conditions for which the lead would become thermally unstable. Aharonian investigated a scenario in which the coolant flow is interrupted to the lead, and what time constants are present.

In this study, a detailed numerical thermal mode. of a SSC power lead has been developed, which was adapted from the dynamic model developed by Schiesser [1]. The transient behavior of the power leads was modeled using a method of lines (MOL) approach. The model was developed to provide a tool for analyzing coolant control strategies as well as an understanding of the behavior of the leads under presumed system transients. Since the SSC leads will be cooled by supercritical helium, the flow of helium is regulated by a control valve. These leads include a superconducting section at the at the cold end to reduce resistive heating, as well as a normal

1. The SSC Laboratory is operated by Universities Research Association Inc. for the U. S. Department of Energy under Contact No.

1

DISTRIBUTION OF THIS DOCUMENT IS UNLIMIY APPROVED FOR RELEASE OR PUBLIGATION - O.R. PATENT GROUP BY...... DATE. $7 \% 3 \% 5$. 


\section{Disclaimer Notice}

This report was prepared as an account of work eponsored by an acency of the Unied Stutes Government. Neither the Uniled States Government or any agency thereof, nor eny of their

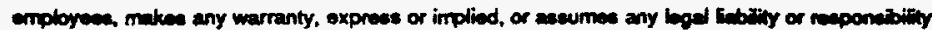

for the eccuracy, comploteness, $\alpha$ usefulness of any information, apparatue, product, or procace diactosed, of represents that its use would not infringe privately owned rights. Retenenos herein to any epecitic cormmercial product. process, or service by trade nams, tradornark manufecturer, or otherwiea, dowe not necessarily constitute or imply ts endorsement, recormmendation, or tevoring by the United States Government or any agency thereot. The viows and opinione of acthore expreseed herein do not necessarily state or neflect those of the United States Govemment or any apency thereof.

Superconducting Super Collider Laboratory is an equal opportunity employer. 


\section{DISCLAIMER}

Portions of this document may be illegible in electronic image products. Images are produced from the best available original document. 
conducting copper section at the top end. The properties of these materials and of the helium are programmed as functions of temperature in the model. Pressure is also included in the calculation of the He properties, although the pressure drop along the lead is not taken into account since it will be small.

\section{POWER LEAD DESCRIPTION}

The lead structure is made up of two sections as depicted in figure 1. The power lead has a core diameter of $1.59 \mathrm{~cm}$. There are approximately 3.15 fins $/ \mathrm{cm}$. The fin thickness and spacing are $0.159 \mathrm{~cm}$. The depth of the spiral fins was held constant at $1.18 \mathrm{~cm}$. providing a constant cross sectional area of $0.188 \mathrm{~cm}^{2}$ for the helium flow. A Nb-Ti superconductor cable surrounded by a copper casing is included in the first $30 \mathrm{~cm}$. of the leads length. The cable has a rectangular cross section given as $0.813 \mathrm{~cm} . \times 0.305 \mathrm{~cm}$. resulting in a cross sectional area for the $\mathrm{Nb}-\mathrm{Ti}$ of $0.248 \mathrm{~cm}^{2}$. An assumed copper to superconductor ratio for the cable of 1.67 was alsc used in this model. The remainder of the lead core is solid copper. The total length of the lead is $76.64 \mathrm{~cm}$. for the accelerator system string test (ASST) leads and $83.5 \mathrm{~cm}$ for prototype leads tested at Fermi National Atomic Laboratory (FNAL) not including the end hardware used to connect to connect to the power supply or to the cryogenic device. The whole lead is convective cooled by liquid helium that enters at $4 \mathrm{~K}$ and a pressure of 4 atmospheres. The cooling passages spiral around the outside of the lead removing heat from the lead. Heat transfer results from two sources that include conduction from the room temperature environment to the cryogenic helium conditions at the cold end, and from intemal heat generation from the resistance of the lead to the flow of electrical current.

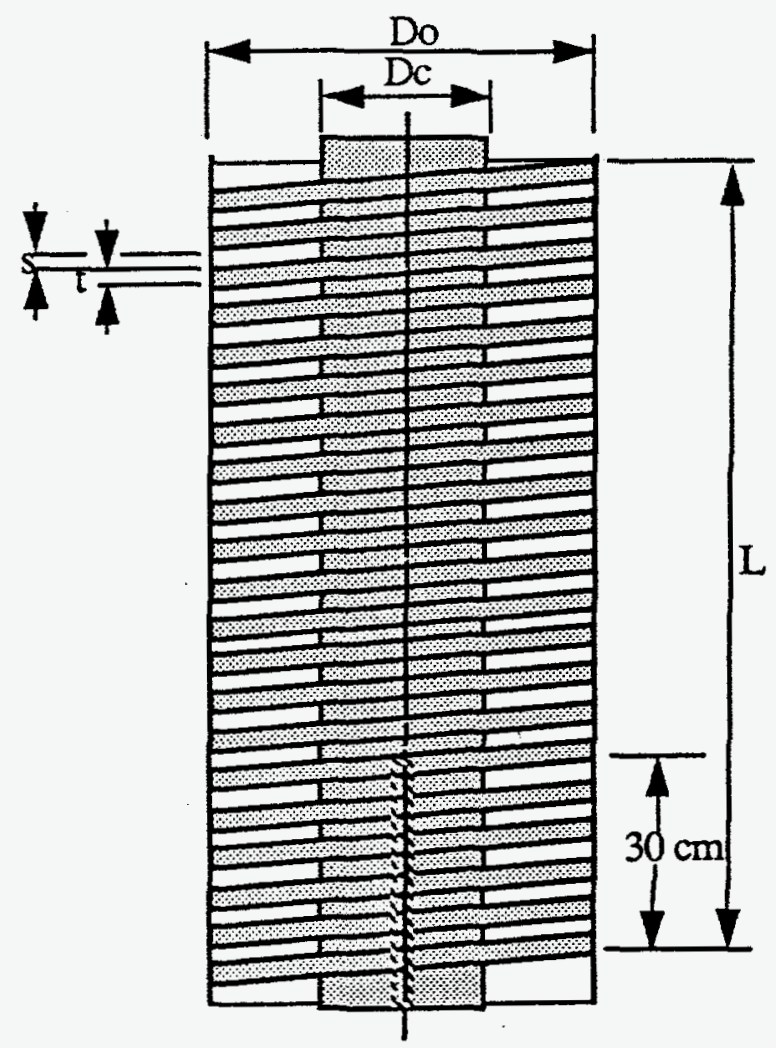

Figure 1: Spiral fin helium cooled current lead concept

\section{MODELING EQUATIONS}

The power lead transient thermal analysis was modeled by applying an energy balance to the solid conductor and the helium. The objective of the modeling was to compute the helium and conductor temperatures as a function of time and position along the lead; thus one-dimensional PDE's resulted from the modeling. The equations are for the solid:

$$
\frac{\partial}{\partial t}\left(\rho_{c} e_{c}\right) d v=\frac{\partial}{\partial x}\left(k A \frac{\partial T_{c}}{\partial x}\right) d x+h_{c o n v} P\left(T_{c}-T_{v}\right) d x+Q_{j}
$$

and for the helium: 


$$
\frac{\partial}{\partial t}\left(\rho_{\nu} e_{\nu}\right) d v=\dot{\dot{m}} \frac{\partial h_{\nu}}{\partial s} d s+h_{c o n v^{v}}{ }^{v}\left(T_{\nu}-T_{c}\right) d x
$$

In these equations, $e_{c}$ and $e_{v}$ represent the intemal energy of the conductor and the helium vapor respectively, $\rho_{c}$ and $\rho_{v}$ refer to the density of the conductor and helium vapor, $\mathrm{h}_{\mathrm{v}}$ is the helium vapor enthalpy, $\mathrm{h}_{\text {conv }}$ is the convective heat transfer coefficient and $\mathrm{P}$ is the convection surface area per unit length of the lead, $m$ is the helium mass flow rate, $T_{v}$ and $T_{c}$ are the helium and conductor temperatures respectively. The quantities $\mathrm{dv}, \mathrm{dx}$, and $\mathrm{ds}$ are the differential conductor volume, differential distance measured along the axis of the lead, and the differential distance measured along the flow path of the helium respectively, for which the energy balance is written.

The joule heating is determined from the following relation:

$$
Q_{j}=\frac{\rho_{\text {elec }} I^{2}}{A_{\text {elec }}} d x
$$

where the quantities $\rho_{\text {elec }}$ and $A_{\text {elec }}$ refer to the electrical resistivity of the lead, and the cross sectional area for electrical conduction.The first term of the right hand side of the helium energy equation can be written in terms of $x$ using the relation:

$$
d x=(\pi \times P i t c h \times D) d s
$$

This formulation can be simplified further. It was determined that the heat capacity of the helium was very small compared to the solid conductor, so it may be neglected. By applying an upwind finite difference technique to the enthalpy derivative, the helium energy equation becomes an algebraic expression for determining the helium liquid temperature.

The heat transfer coefficient is determined from a Dittus-Boelter relation when the flow is turbulent $(\operatorname{Re}>2000)$ given in Wilson [9] and for laminar flow the Nusselt number based on the aspect ratio of the channel is a constant from Kays [10]. The heat transfer coefficient is given by the following equations for these two flow regimes:

$$
\begin{gathered}
N u_{\text {laminar }}=\frac{h_{\text {conc }} D_{h y d}}{k_{v}}=6.6 \\
N u_{\text {turbulent }}=\frac{h_{\text {conv }} D_{h y d}}{k_{v}}=0.0259 \operatorname{Re}^{0.8} \operatorname{Pr}^{0.4}\left(\frac{T_{v}}{T_{c}}\right)^{0.716}
\end{gathered}
$$

In the model, the convection area included two sides of the channel and the channel base. The channel sides were assumed to be isothermal in the radial direction. The resulting algebraic expression for the helium energy balance becomes:

$$
\dot{m}\left(\frac{h_{i}-h_{i-1}}{\Delta x}\right)=h_{c o n v} P\left(T_{c}-T_{\nu}\right)_{i}
$$

The enthalpy term and the convective heat transfer coefficient are evaluated using the conductor temperatures at a given time. This equation can then be used to solve for the new values of the helium vapor temperature along the lead since $h_{i}=h_{i}\left(T_{v}\right)$. This approximation is acceptable because the thermal capacitance of the helium is very small in comparison to the lead. Thus the helium temperature changes almost instantaneously with a change in the lead temperature.

The mass flowrate of the helium was set using a proportional-integral (PI) control algorithm which adjusted the mass flowrate of the helium to maintain the temperature at the top of the lead at a set point. The equation which describes this control action is:

$$
\dot{m}=K_{g} \times\left(\left(T-T_{s e t}\right)+\frac{I}{\tau} \times \int_{0}^{\tau}\left(T-T_{\text {set }}\right) d t\right)
$$

The first term represents the proportional controller with a gain of $\mathrm{K}_{\mathrm{g}}$ and the second term is the integral action with a time constant $\tau$. This additional ordinary differential equation was integrated as part of the solution to provide the mass flow at each time step. 
To solve the resulting system of partial differential equations, the numerical metrci of lires approach was used as discussed in Schiesser [11]. In this method, the first term on the right hand side of the equation (1), winch represents the net conduction heat transfer along the lead, was cast into a finite difference form given by:

$$
\frac{\partial}{\partial x}\left(k A_{c} \frac{\partial T_{c}}{\partial x}\right)=(k A){ }_{i+\frac{1}{2}}\left(\frac{T_{i+1}-T_{i}}{\Delta x}\right)-(k A){ }_{i-\frac{1}{2}}\left(\frac{T_{i}-T_{i-1}}{\Delta x}\right)
$$

The temperature dependent thermal conductivities at the $i+1 / 2$ and $i-1 / 2$ locations were computed based on the geometric mean as recommended by Patankar [12].

$$
k_{i+\frac{1}{2}}=\frac{2 k_{i+1} k_{i}}{k_{i+1}+k_{i}}
$$

The lead conduction cross sectional area is constant except for the prototype lead, which was used to take experimental measurements, which has a hollow section at the top. For this case, the area of the hole is simply subtracted out of the lead cross section. At the interface region, the proper area is used for the $\mathrm{i}+1$ and $\mathrm{i}-1$ locations. A fixed temperature boundary condition was applied at the cold end $\mathrm{X}=0$. At the warm end the lead transferred heat to the environment at $300 \mathrm{~K}$ through an overall heat transfer coefficient determined from calibration of the model with experiments.

The material properties of the conductor were taken for $\mathrm{OFHC}$ copper with a $\mathrm{RRR}=40$. The properties of the $\mathrm{Nb}-\mathrm{Ti}$ superconductor were based on a copper to superconductor ratio of 1.67. Material properties were determined from a database used at the SSC lab [13], from Collings [14], and Reed and Clark [15]. Special consideration is also required for the superconducting section in calculating the composite thermal conductivity and the electrical current flow when the superconducting transition occurs in this region. The thermal conductivity as a function of temperature was obtained for the $\mathrm{Nb}-\mathrm{Ti}$ from Collings [14]. A linear interpolation of all the conductor properties is utilized. The thermal conductivity of the composite region was based on a simple area weighted average of the thermal conductivities. When the $\mathrm{Nb}$ - $\mathrm{Ti}$ cable is in a superconducting state (i.e. $\mathrm{T}<\mathrm{T}_{\mathrm{cri}}$ ), it is assumed that the electrical resistivity becomes that of the copper stabilizing the superconductor (based on a copper to superconductor ratio of 1.67) and that all of the current flows through the superconducting cable. The critical temperature was taken to be $10.2 \mathrm{~K}$ assuming no magnetic field [14].

Upon making the above algebraic substitutions for the spatial derivatives and applying the required boundary and initial conditions, a system of ordinary differential equations in time results. The LSODES integrator was used to solve the resulting system of ordinary differential equations. A total of 51 equally spaced nodes were used in the model. Spatial convergence was checked by comparing solutions for 101 and 51 equally spaced points.

\section{RESULTS AND DISCUSSION}

A comparison of the results of a dynamic simulation of the prototype current leads with data taken at FNAL in 1991 has been made to demonstrate that the important operating characteristics of the current lead are being emulated, and to provide a quantitative assessment of the accuracy of the model. This is necessary since the model has been applied to the design of the current leads for the ASST and to the choice of control scheme. In addition, the model will be used for the dynamic simulation of the SSC current leads and the development of control strategies.

The test conditions simulated were for the data taken on April 18,1991. The test was conducted by ramping up the current at 6 amps/sec until a maximum current of 4970 amps was reached. The current was held constant for about 1300 seconds and then ramped down at 12 amps/sec. The helium mass flow controller had a gain of 0.45 and an integral reset time of 200 seconds. The set point temperature was 253 K.Measurements were made of the helium mass flow through the lead, as well as temperature and voltage at several locations along the lead. The assumed initial starting temperature profile for the lead was determined from a cubic spline fit of the measured data along the lead. A comparison of the cubic spline and the measured data are in good agreement everywhere except for X $<20 \mathrm{~cm}$, as shown in figure 2 . This is because a fixed temperature boundary condition was applied on the helium and current lead temperature that is lower than the initial measured temperature of the lead at $X=0$. A PI mass flow control loop was also simulated using the experimental values for the set point, controller gain, and integral reset time. The predicted and measured mass flow results are provided in figure 3 . When the control system is activated, it fully opens the helium flow control valve and produces the initial spike in the mass flow data. The qualitative shape of the mass flow curve is predicted well by the model with the largest discrepancies occurring for times less than 650 seconds and greater than 2400 seconds. The predicted mass flow results agree fairly well for the time in between. In order to match the steady state helium mass flow, the overall heat transfer coefficient was varied. The value used was $1 \mathrm{~W} / \mathrm{K}$. 


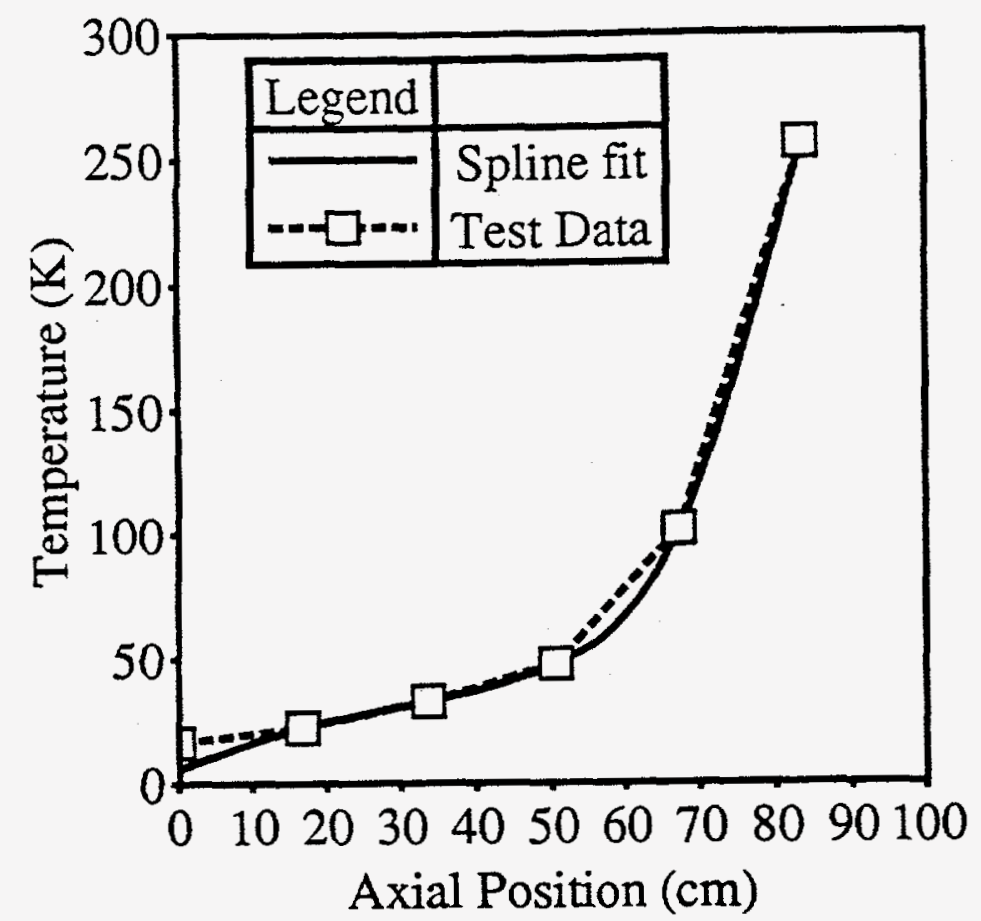

Figure 2: Initial temperature profiles

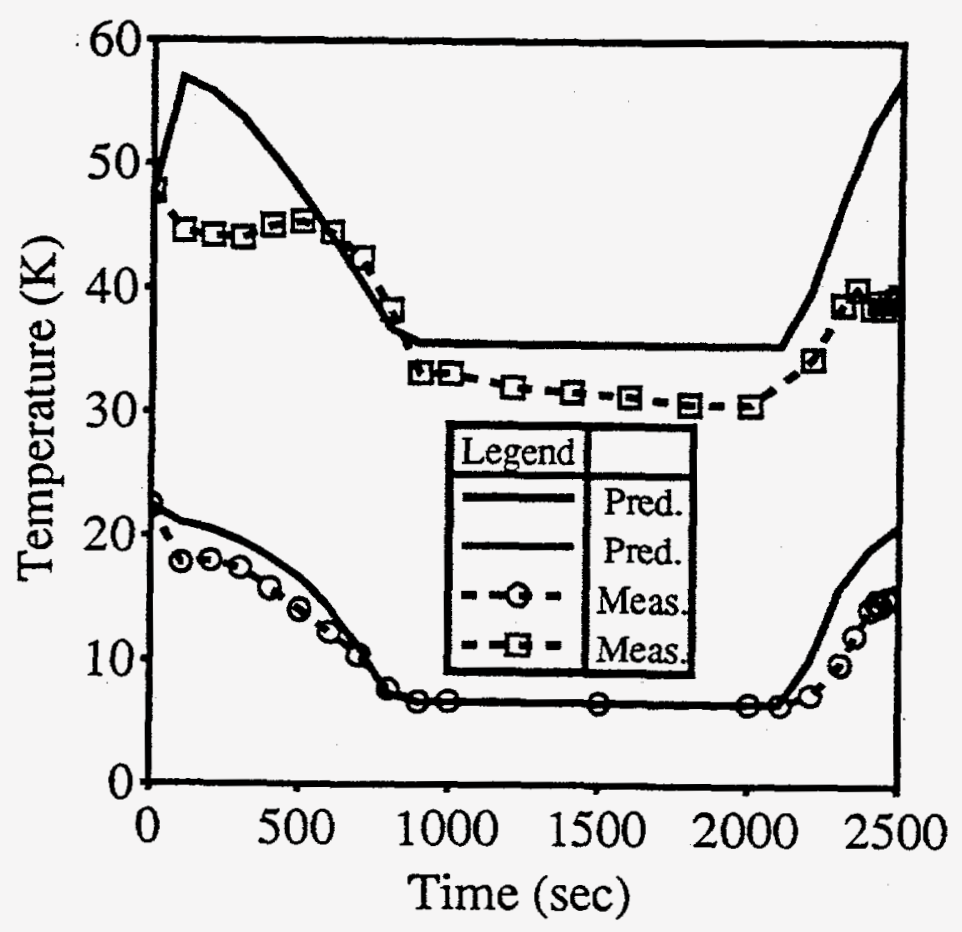

Figure 4: Predicted and measured temperature histories at two axial locations

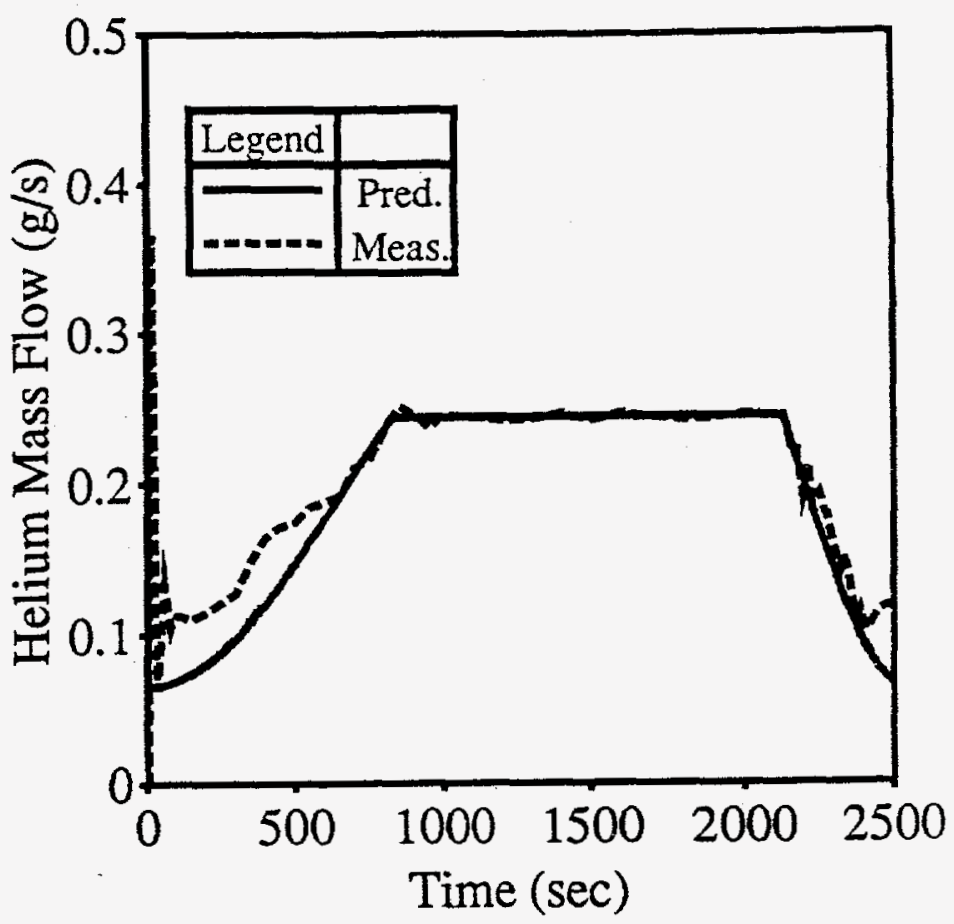

Figure 3: Predicted and measured helium mass flowrate

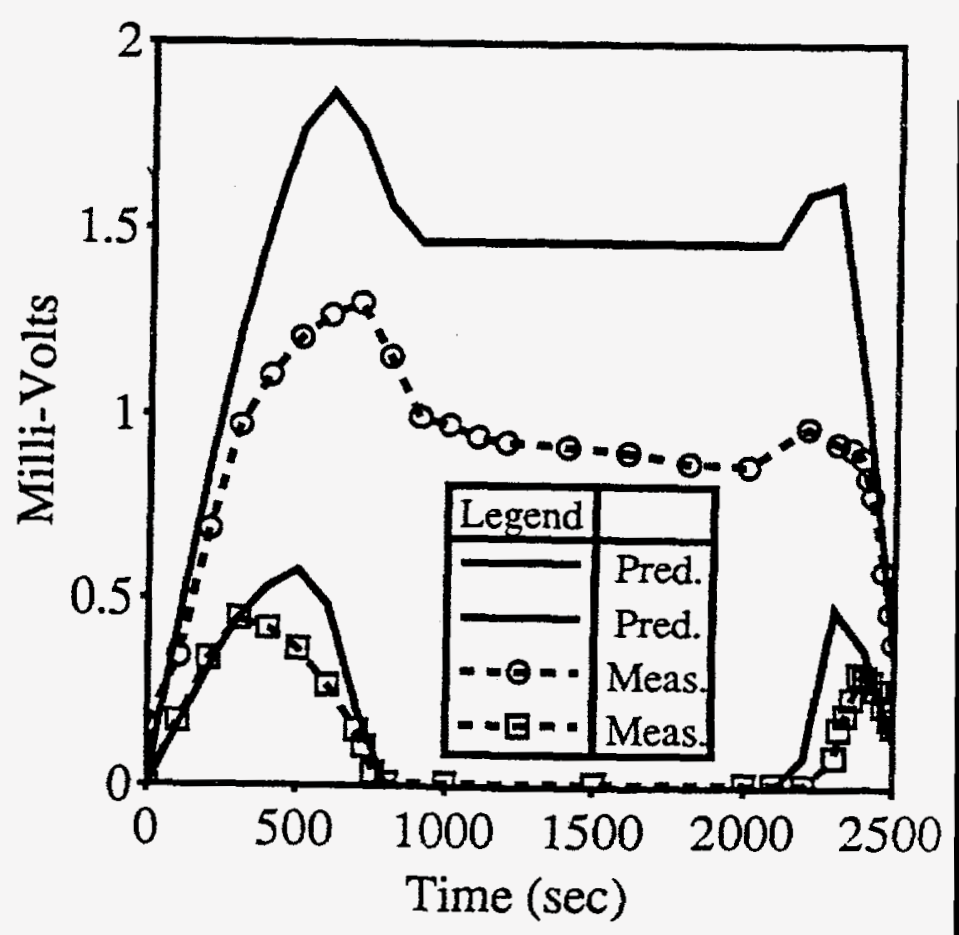

Figure 5: Predicted and measured voltage histories at two axial locations 
Figure 4 presents the transient temperatures at two axial locations measured from the bottc:.. of une lead. The lower curves are for $X=16.73 \mathrm{~cm}$ and the upper curves are for $X=50.48 \mathrm{~cm}$. The temperatures at the colder location initially decrease in both the prediction: and measurements. A steady value is reached after about 900 seconds as the current reaches its plateau value. The temperature at this location begins to rise for time later than 2130 seconds, as the current is ramped down and the helium cooling flow correspondingly decreases.

The temperature predictions at the $50.48 \mathrm{~cm}$ location initially increase contrary to the measurements and then follow the measured trends. The discrepancy is partly due to the higher electrical dissipation predicted by the model as shown in the comparison of the predicted and measured voltages at the two stations shown in figure 5. The higher voltages predicted by the model, are much closer to the measurements at $X=17.94 \mathrm{~cm}$ (the lower curve). At this location, the voltage initially increases since the temperature is above the critical temperature for $\mathrm{Nb}$ - Ti, and as the superconducting transition travels up the lead, the voltage drops. At about 800 seconds, this location becomes superconducting and there is no electrical resistance at this location on the lead. The behavior at the $\mathrm{X}=38.26 \mathrm{~cm}$ (the higher curve) show similar trends, but will not drop to 0 volts since this location is in the completely copper section of the lead.

The location of the superconducting transition predicted from the model is shown in figure 6 . The experimental data points are the times which the voltage reached a value of $10^{-5}$ volts at two taps. The horizontal dashed line at $X=28.1 \mathrm{~cm}$ represents the first voltage tap which indicated a resistive state in the portion of the lead containing $\mathrm{Nb}$ - $\mathrm{Ti}$ during the constant current portion of the test. The predictions of the location of this transition indicate a slower growth of the superconducting region during the ramp up, and a faster shrinkage of this region during the ramp down. The transition velocity may be deduced from these data. For the initial ramp up just pric to the constant current time span, the corresponding predicted and measured transition velocities are $0.0544 \mathrm{~cm} / \mathrm{sec}$ and $0.0686 \mathrm{~cm} / \mathrm{sec}$ respectively. For the ramp down these velocities are $-0.0822 \mathrm{~cm} / \mathrm{sec}$ and $-0.0540 \mathrm{~cm} / \mathrm{sec}$ for the predictions and measurements respectively. Thus the model predicts a $21 \%$ slower growth of the superconducting length and a $34 \%$ faster abatement of the superconducting length.

In figure 7 the transient temperature distribution along the lead is shown, at 20 second intervals, for a scenario in which the lead is operating at a steady state condition at $6.5 \mathrm{kA}$ with a steady helium flowrate of $0.31 \mathrm{~g} / \mathrm{s}$. The cooling flow is abruptly stopped and the current continues to flow at $6.5 \mathrm{kA}$. The maximum temperature occurs inside the lead and not at the top end. This case illustrates the application of the model to predicting the off-design behavior of the lead.

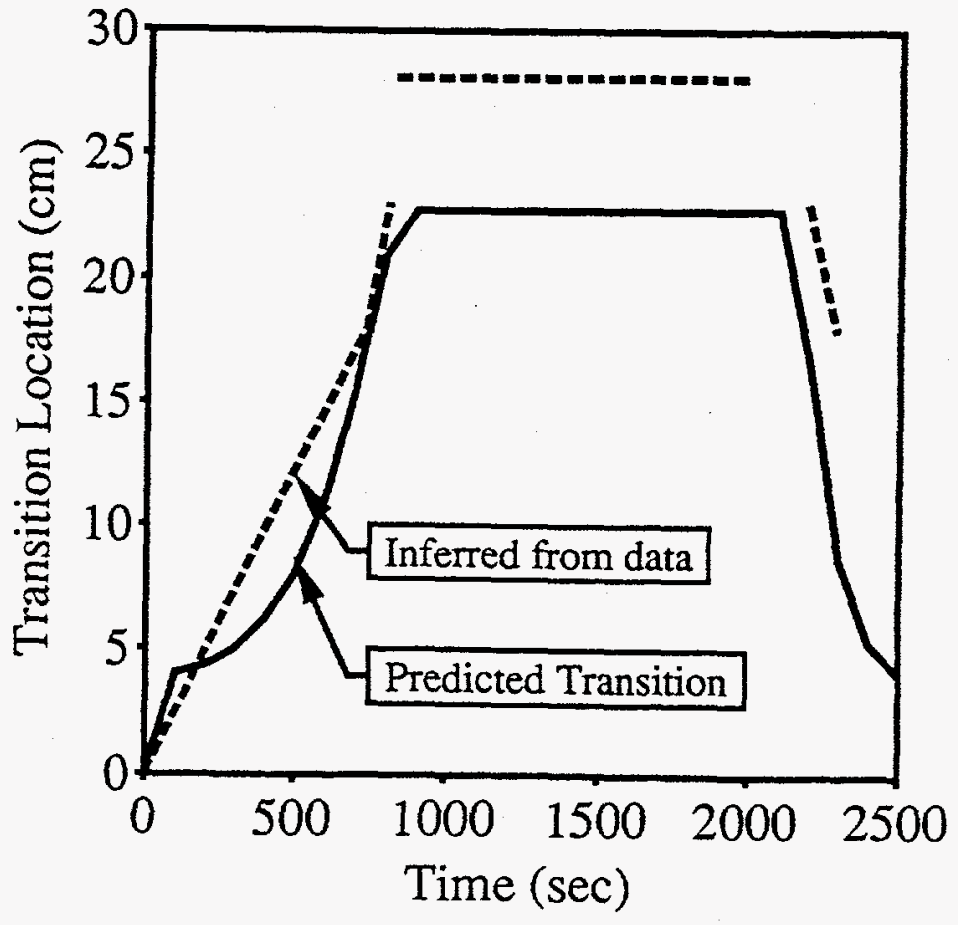

Figure 6: Location of superconducting transition

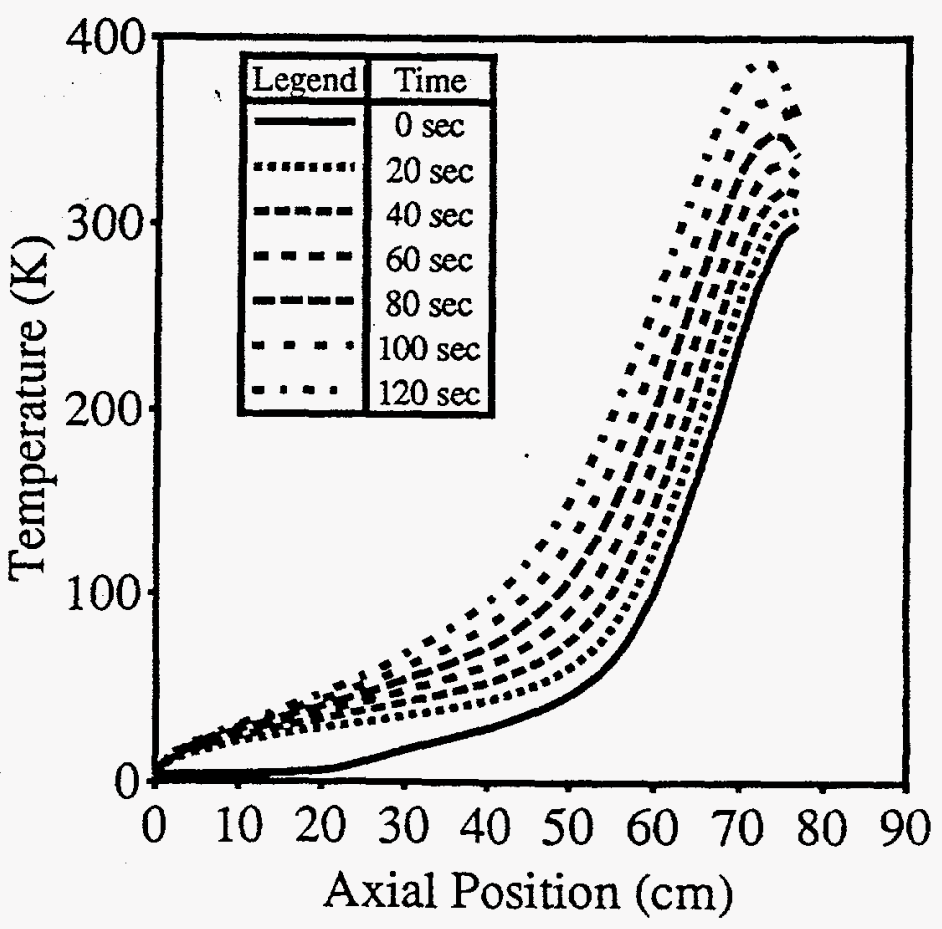

Figure 7: Temperature distributions for coolant interruption at $6.5 \mathrm{kA}$ 


\section{SUM HARY AND CONCLUSIONS}

A method of lines solution procedure has been employed to determine the transient temperature and voltage distributions in a prototype 6500 amp current lead for the Superconducting Super Collider. The predictions qualitatively agree with the measured data except for some early times. This difference can be attributed to errors in the initial temperature profile and to the cold end boundary condition applied in the model. Since the cold end $(X=0)$ temperature of the lead initially decreased with time according to measurements, a temperature gradient (i.e. convective heat transfer) boundary condition is more appropriate for the cold end of the lead. Good agreement has been obtained between the measured and predicted mass flow of helium. The model predicts the qualitative transient behavior of the lead fairly well.

\section{REFERENCES}

1. W. E. Schiesser, “A Dynamic Model of the SSC Power Leads”, SSC Laboratory Informal Report, August 1990

2. J. R. Sandford and D. M. Matthews," Site-Specific Conceptual Design of the Superconducting Super Collider", SSCL-SR-1056, July 1990

3. R. McFee,"Optimum Input Leads for Cryogenic Apparatus", The Review of Scientific Instruments, Volume 30, Number 2, February 1959

4. Yu. L. Buyanov, "Current Leads for Use in Cryogenic Devices. Principle of Design and Formulae for Design Calculations", Crvogenics, Vol. 25, February 1985

5. Maehata, M., Ishibashi, K., Wake, M., Katase, A., And Kobayashi, M.,"Optimization Method for Superconducting Magnet Current Leads", Crvogenics, Vol. 28, November 1988

6. Demko, J. A., Schiesser, W. E., Carcagno, R., McAshan, M., and McConeghy, R.,'Themal Optimization of the Helium Cooled Power Leads for the SSC', Presented at the IISSC, New Orleans, La., March 1992

7. Jones, M. C., Yeroshenko, V. M., Starostin, A., and Yaskin, L. A.'Transient Behavior of Helium-Cooled Current Leads for Superconducting Power Transmission", Cryogenics, June 1978

8. Aharonian, G., Hyman, L. G., and Roberts, L.,"Behaviour of Power Leads for Superconducting Magnets", Crvogenics, March 1989

9. Wilson, M. N., Superconducting Magnets, Clarendon Press, Oxford, 1982

10. Kays, W. M., “Convective Heat and Mass Transfer”, McGraw-Hill, 1966

11. Schiesser, W. E., "The Numerical Method of Lines Integration of Partial Differential Equations", Academic Press, San Diego, 1991

12. Patankar, S. V., “Numerical Heat Transfer and Fluid Flow”, Hemisphere Publishing Corporation, 1980

13. Devred, A., SSC Laboratory, Intemal Communication

14. Collings, E.W. “Applied Superconductivity, Metallurgy, and Physics of Titanium Alloys”, Plenum Press, 1986

15. Reed, R. P., and Clark, A. F., "Materials at Low Temperatures", American Society for Metals, 1983 